\title{
DENTAL COMPUTER TOMOGRAPHY IN THE PRACTICE OF ORTHOPEDIC DENTISTRY
}

\author{
Nazarov Olimjon Jabborovich, Gaybullaeva Yulduz Hamidovna \\ olimnazarov@mail.ru \\ yulduz0706@gmail.com \\ ORCID ID orcid.org/0000-0002-7144-7286 \\ ORCID ID orcid.org/0000-0003-4618-1559
}

Tashkent institute of postgraduate medical education, Tashkent, Republic of Uzbekistan

\section{Crossref}

http://dx.doi.org/10.26739/2433-202x

Issue DOI http:/ / dx.doi.org/10.26739/2433-202x-2017-6-6

Article DOI http:/ / dx.doi.org/10.26739/2433-202x-2017-6-6-4

Analyzing results of the CBCT method the average anatomic parameters of anterior point of HIP (Hamulus-Incisive Papilla) plane related to the terminal hinge axis of the mandible were detected. The obtained data give more opportunities to develop adjustable appliances for mounting the plastic casts on diverse types of articulators in the correct average anatomic position. This will promote to improve the quality of diagnosis and treatment of various types of anomalies of teeth, dental arches and jaws with dental prostheses and orthodontic appliances. 
Key words: Dental computer tomography, HIP-plane, terminal hinge axis, occlusal plane

The approach to dental treatment for many years was based on the axiomatic assertion that the lower jaw is a more important bone than the upper one, which forms the basis of occlusion. The generally accepted standard was the use of the Camper, Frankfurt and hinge-orbital planes as landmarks (parallel to the latter, a face bow was usually installed), as well as the transversal hinged axis passing through the centers of the joint heads. Nevertheless, we came to the conclusion that the upper jaw is the basic one, and the generally accepted horizontal planes-landmarks are not horizontal; that the lower jaw has an initial rotation within $10^{\circ}$, the center of which is the bilaminar zone, i.e. center between the anterior wall of the external auditory canal and the distal wall of the head of the lower jaw, and aligning the facial bow along the articulated orbital axis does not make sense [1].

The base of the skull (spheno-occipital or spheno-basilar synchondrosis) is the most important anatomical landmark of the skull. This is a combination of the sphenoid and occipital bones. Through the pterygoid processes of the sphenoid bone by means of the seam, the base of the skull is connected with the palatine bones and through them with the upper jaw.

The maxillary dental arch and articular pits are fixed structures, while the lower jaw is a movable component of the dental system. The upper jaw is a reliable reference point for the analysis and preparation of a treatment plan for disorders in the dental system. HIP-plane - Hamulus-Incisive Papilla, (Hamulus pterygoideus - the process bent in the form of a hook, is an extension of the median plate of the pterygoid process of the sphenoid Health Science Nazarov O., Gaybullaeva Y. 
bone, Incisive Papilla - intercellular papilla), whose reference points are the incisal foramen and the pterygomaxillary recesses[3]. The pterygomaxillary recesses are located in the area of joining the plates of the pterygoid processes of the sphenoid bone with palatine bones. The incisal hole is located in the anterior part of the maxillary arch along the median-sagittal line. It should be noted that the Porion / ANS plane can also be used as a guide in the analysis of the location of the occlusal plane and the structures of the maxillary.

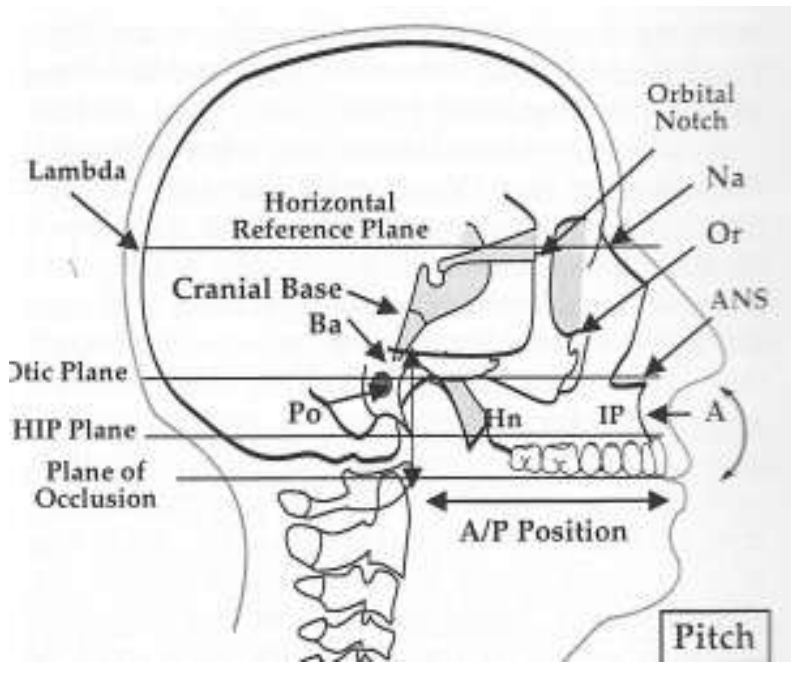

Fig.2. The main planes-orientation points and their relationship with the bones of the base of the skull

This is the most accurate reference point, as it is attached to bone structures (the maxilla, palatine and sphenoid bones), and not to the softtissue structures of the face (such as the nose wing or tragus of the ear). Figure 2 shows that there is a close relationship between the occlusal plane, the horizontal plane and the HIP plane - they are parallel to each other. 

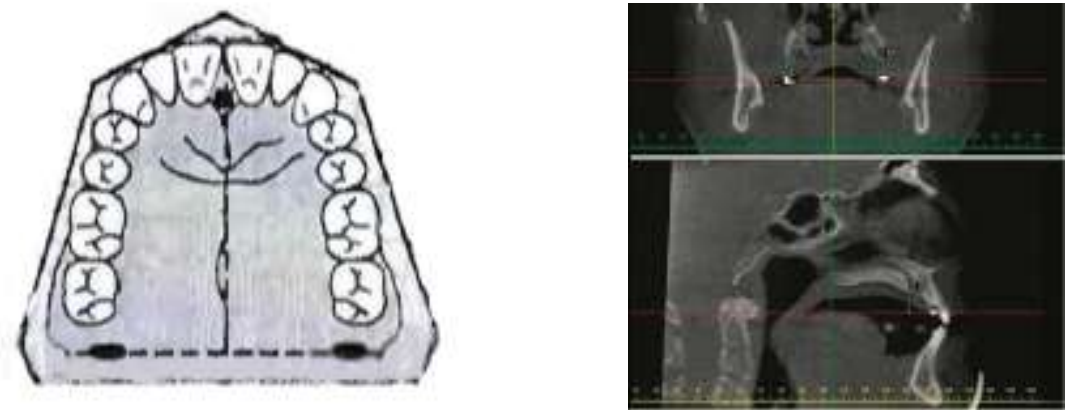

Fig.3. Bony and soft-tissue landmarks of the HIP-plane

The bony landmarks - the incisal foramen and the pterygomaxillary recesses - have the corresponding soft-tissue orientations in the form of the interincisal papilla and the have the pterygomaxillary recesses (fig. 3). Thus, the HIP-plane is both a bone and a soft-tissue guide. It is impossible to determine the bone HIP plane on the patient (this is not an anatomical dissection). The mucous membrane covering the pterygomaxillary recesses is approximately the same thickness as the interincisal papilla. Soft-tissue orientations of the pterygomaxillary recesses are easy to find on most models, unless the maxillary tubers are destroyed due to surgical intervention or bone resorption. It must be taken into account that the size and thickness of interincisal papilla can vary greatly. If the interincisal papilla is too small or large, a compensation correction must be made before mounding the models in the articulator. These soft-tissue orientations are firmly connected with the bony landmarks (incisal hole and bony pterygomaxillary recesses). Either way, in most cases the soft-tissue HIPplane, although slightly shifted from the bone, remains parallel to it. The ideal occlusal plane should be smooth, symmetrical and parallel to the plane passing through the pterygomaxillary recesses and incisal hole, as well as the horizontal plane and perpendicular to the axis of gravity (Fig. Health Science

Nazarov O., Gaybullaeva Y. 
2.3). In the literature we have studied, there is no exhaustive data on the location of the points of the reference points of the HIP plane relative to the terminal hinge axis (Terminal Hinge Axis-THA) of the mandible to which the jaw models are oriented.

Proceeding from the above, the purpose of our research was to determine the average parameters of the topography of the anterior point of the HIP plane related to the terminal hinge axis of the mandible.

Material and methods of research: to achieve this goal, we examined more than 35 volunteers with various diseases of the dentofacial system on the dental computer tomograph Galileos (Fig. 4).

Innovative method of radiation diagnosis - dental 3D computer tomography significantly expands the possibilities of primary and differential diagnosis in outpatient dentistry, maxillofacial surgery and otorhinolaryngology. At the beginning of 2015, one of the first threedimensional dental cone beam computer tomograph "Galileos" was installed in the X-ray diagnostic room (by SIRONA CO., LTD., Germany, the exclusive representative in Uzbekistan - "INVIVO" company, Tashkent). When performing an examination on this dental computer tomograph, the radiation load when scanning the maxillofacial area is commensurate with the dose that the patient receives when producing one or two digital panoramic zonograms of the dentition. Modern 3D stomatology implies the use of the dental computer 3D tomograph "Galileos", which makes it possible to predict and evaluate the immediate and long-term results of implantation, to detect pathological changes, to plan orthodontic treatment and to evaluate this treatment in dynamics. Tomograph "Galileos" has great prospects in dentistry and maxillofacial surgery. 

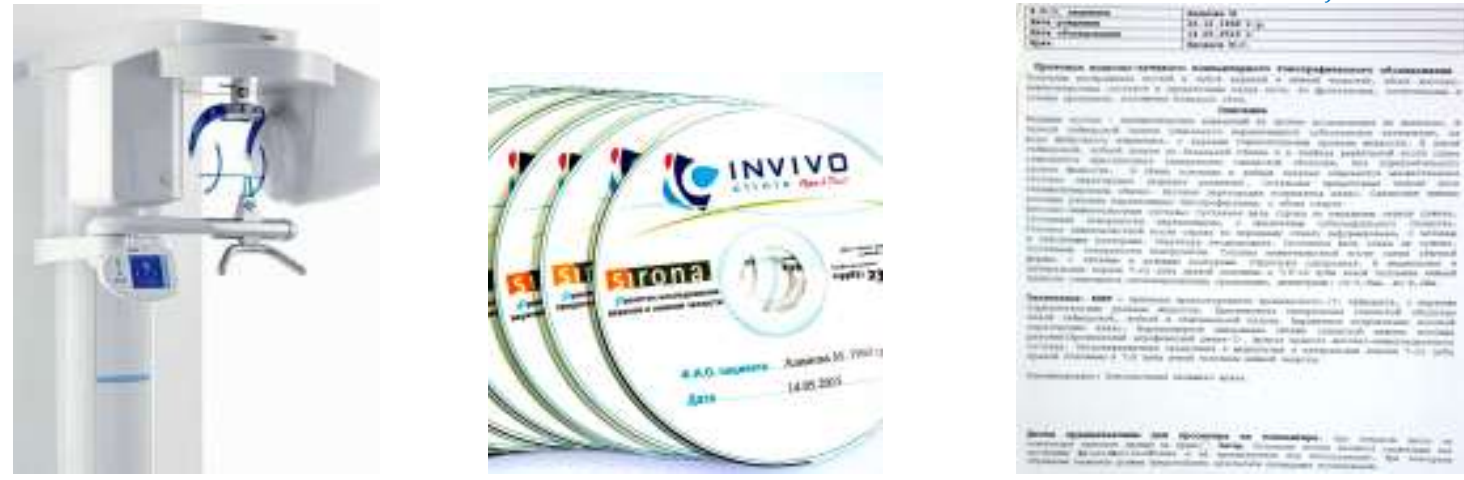

Fig. 4. Dental computer 3D tomograph "Galileos"

The three-dimensional image of the tooth obtained in this study in the sagittal, frontal and horizontal planes reveals a number of anatomical features of the roots and root canals, and more accurately assess the condition of periodontium and parodontium. Based on the data of the threedimensional CT of the dentoalveolar system, linear and angular measurements can be made, a pseudo-3D image of bone structures and soft tissues can be constructed, a comparative densitometry of the periapical tissues of the teeth and alveolar processes of the jaws can be made. The dimensions of the maximum examination area for dental CT $-15.4 \times 15.4 \times$ $15.4 \mathrm{~cm}$ (sensor dimensions), the width of sections in all planes is $0.1 \mathrm{~mm}$; exposure time - $24 \mathrm{sec}$. The effective equivalent dose of radiation that a patient receives when performing a three-dimensional dental $\mathrm{CT}$ on the apparatus "Galileos" is minimal, information is recorded on a CD-ROM. Three-dimensional dental computer tomograph «Galileos» (SIRONA CO., LTD., Germany) allows: differential diagnosis of dental caries complications and determine the optimal technique and tactics for endodontic treatment; expands the possibilities in diagnosis of temporomandibular joints, external auditory canal, middle and inner ear; allows to predict and evaluate the long- 
term results of dental prosthetics in patients of dental clinics; plan tooth implantation and various bone-plastic surgical interventions, including in the zone of the bottom of the maxillary sinuses and the mandibular canal; to reveal pathological changes on the part of the maxillary sinuses and the nasal cavity; allows to diagnose anomalies in the development of teeth and jaws in adults and children.[2]

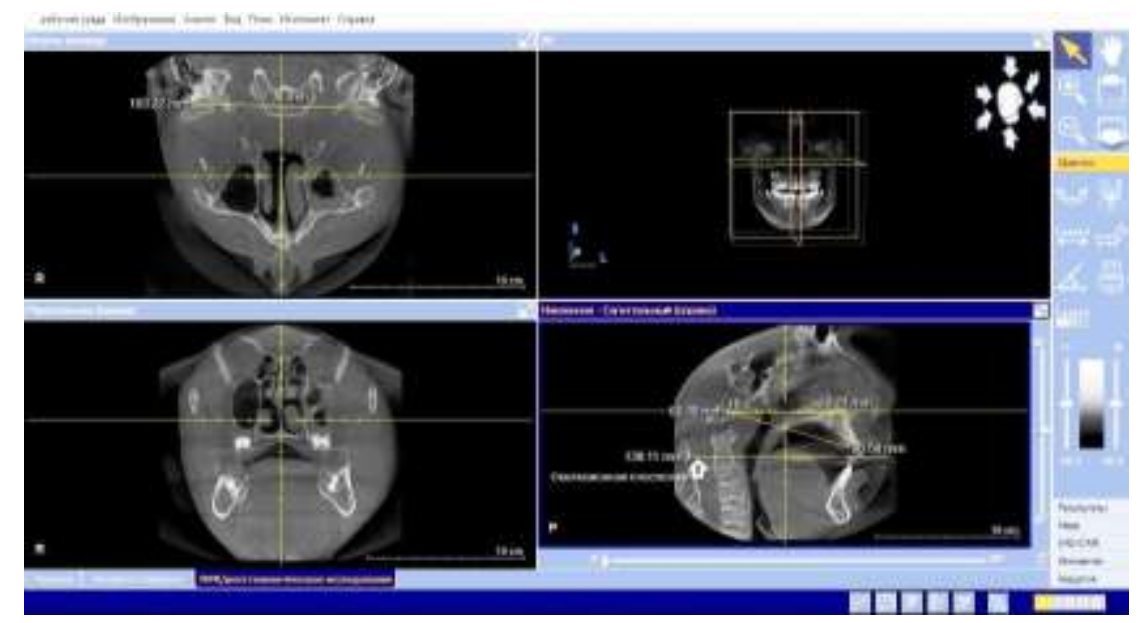

Fig. 5. In the process of analyzing the obtained CT data.

The three-dimensional image allows to carry out measurements in three planes, visualize the mandibular canal and the cervical cortical plate of the bottom of the maxillary sinuses. Then the information is recorded on a CDROM, which can be viewed on the personal computer of a dentist in the clinic without using a special computer program of three-dimensional reconstruction of tomographic sections (Fig. 5).

\section{The results and discussions.}

We conducted a clinical-stomatological examination of a group of volunteers consisting of 35 people with orthognathic occlusion (without dental anomalies), among them men - 20, women - 15 people.

Distribution of the examined persons. 


\begin{tabular}{|c|c|c|c|c|c|}
\hline \multicolumn{6}{|c|}{ Characteristic } \\
\hline \multirow{2}{*}{$\begin{array}{c}\text { Age } \\
\text { (years) }\end{array}$} & \multirow[b]{2}{*}{ Total } & \multirow[b]{2}{*}{ Men } & \multirow[b]{2}{*}{ Women } & \multicolumn{2}{|c|}{ Chewing side } \\
\hline & & & & Right & Left \\
\hline $30-39$ & 35 & 20 & 15 & 35 & 35 \\
\hline Total & 35 & 20 & 15 & 35 & 35 \\
\hline
\end{tabular}

Clinical signs of the absence of functional disorders in the TMJ were determined, which were as follows: face configuration symmetrical; palpation of the joint at rest, when opening and closing the mouth painless; mouth opening is free, opening degree of mouth is $45-50 \mathrm{~mm}$; movement of the lower jaw from the position of the central occlusion - in the lateral, in the anterior and backward direction with closed dentition smooth; sound phenomena, on the part of the joint, absent; movements of the lower jaw when opening and closing the mouth are strictly vertical, without deviation to the sides and a zigzag shift; palpation of the masticatory muscles is painless.

At the stage of instrumental examination of the surveyed persons, we obtained a three-dimensional image of the stomatotonagic system, which made it possible to perform measurements in three planes, visualize the topography and the distance of the reference points (Terminal Hinge Axis, Incisal Papilla).

When carrying out geometrical measurements of the obtained CT data on a computer, it was revealed that the distance between the points of THA and IP averaged $86.6 \pm 5.0 \mathrm{~mm}$. The distance from the IP point to the Porion / ANS plane averaged $24.4 \pm 3.0 \mathrm{~mm}$. When connecting points THA, ANS and IP, we obtain a right triangle with the legs THA / ANS, IP / ANS and the Health Science Nazarov O., Gaybullaeva Y. 
hypotenuse TNA / IP, as well as the angles THA, IP and ANS. The right angle in this rectangular triangle is the angle ANS. The remaining angles of the right triangle were calculated according to the generally accepted formula (Table-1).

Table-1

Indicators of geometric measurements of the HIP plane obtained from computed tomography.

\begin{tabular}{|c|c|c|c|c|c|c|}
\hline $\begin{array}{c}\text { Total } \\
\text { examined }\end{array}$ & M / F & $\begin{array}{c}\text { Age } \\
(\text { years })\end{array}$ & $\begin{array}{c}\text { THA/IP } \\
(\mathrm{mm})\end{array}$ & $\begin{array}{c}\text { IP/ANS } \\
(\mathrm{mm})\end{array}$ & $\begin{array}{c}\text { Angle } \\
\text { THA } \\
\text { (degree) }\end{array}$ & $\begin{array}{c}\text { Angle } \\
\text { IP } \\
(\text { degree })\end{array}$ \\
\hline 35 men. & $20 / 15$ & $30-50$ & $86.6 \pm 5.0$ & $24.4 \pm 3.0$ & $16.2 \pm 0.3$ & $73.8 \pm 0.3$ \\
\hline
\end{tabular}

In conclusion, we can say that the IP point is from THA at an average distance of $86.6 \pm 5.0 \mathrm{~mm}$ at an angle of $16.2 \pm 0.3$ degrees with respect to the Porion / ANS or THA / ANS plane, since the Porion, THA and ANS points lie in one horizontal plane (Fig.6.).
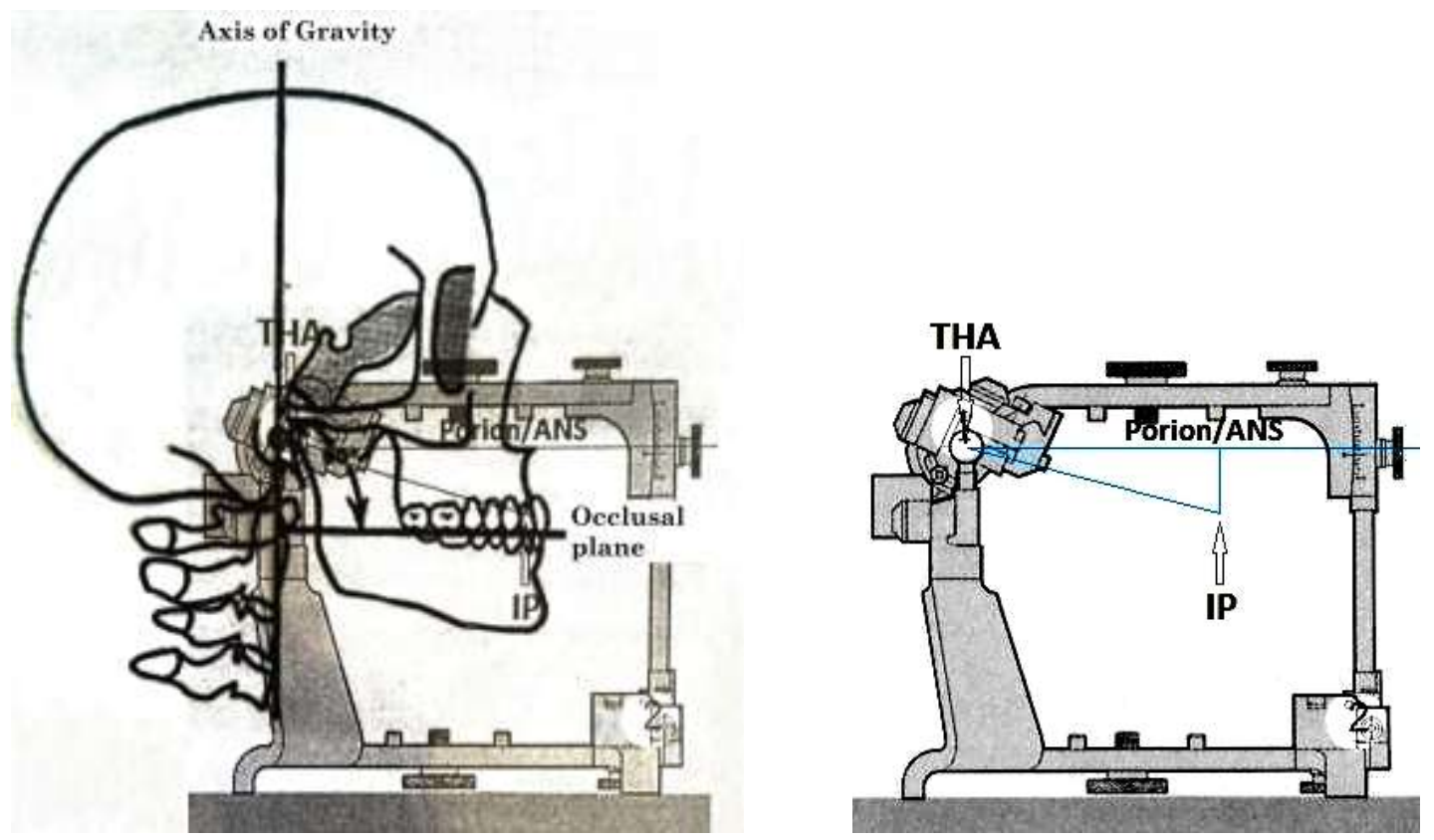

Fig. 6. Arrangements of the THA-ANS-IP triangle in the human skull and in Health Science Nazarov O., Gaybullaeva Y. 
the articulator

Our experience in the use of three-dimensional dental computer tomography on the apparatus "Galileos" (SIRONA CO., LTD., Germany) demonstrates the high information value of the technique and indicates the need to develop new adjustable devices for correctly fixing the jaw models into the inter-frame space of various types of articulators. This in turn excludes the occurrence of possible errors in the laboratory stages of manufacturing various dentures and improves the quality of diagnosis and treatment of tooth pathologies, dentition and maxillofacial area by orthopedic prostheses and orthodontic appliances. 


\section{References}

1. Nazarov OZ, Gaibullaeva Yu.Kh. The terminal hinge axis of the mandible - Modern views // American Journal of Research №5(5), May 2017- P. 127-134.

2. Chibisova M.I. Possibilities of clinical application of a dental computer tomograph in a multidisciplinary dental clinic / / Institute of Stomatology. № 4. - 2007. - P. 124.

3. Carlson J. E. Physiologic occlusion.//Midwest Press. - 2009. - 219 p. 